Check for updates

Cite this: Chem. Commun., 2017, 53, 9922

Received 20th June 2017

Accepted 15th August 2017

DOI: $10.1039 / \mathrm{c} 7 \mathrm{cc} 04803 \mathrm{c}$

rsc.li/chemcomm

\section{Unusual reactivity of rhodium carbenes with allenes: an efficient asymmetric synthesis of methylenetetrahydropyran scaffolds $\dagger$}

\author{
Òscar Torres, (D) Miquel Solà, (D) Anna Roglans (D) and Anna Pla-Quintana (D)*
}

\begin{abstract}
A Rh'/(S)-BINAP catalytic system is able to promote carbene alkyne metathesis and cascade this elemental step with an stereoselective reaction with allenes. An unusual carbene/allene reactivity is discovered that, through a formal addition of $\boldsymbol{p}$-toluenesulfinic acid to a Rh-bound trimethylenemethane intermediate, affords 4-methylenetetrahydropyran compounds in good yields and excellent enantioselectivities.
\end{abstract}

Metal carbenes are versatile reaction intermediates that can react with a wide variety of functional groups to synthesize complex organic molecules with high levels of chemo-, diastereo-, and enantioselectivity. ${ }^{1}$ The reaction of metal carbenes with alkenes to afford cyclopropanes has been extensively and systematically studied. ${ }^{2}$ In contrast, their reaction with allenes has received much less attention. In these latter reactions, alkylidenecyclopropanes are normally formed through a formal [2+1] cycloaddition. ${ }^{3}$ However, formal [3+2] cycloadditions, which afford cyclopentenes containing an exocyclic double bond, are observed when vinyl carbenes are reacted. ${ }^{4}$

We recently reported that $\mathrm{Rh}^{\mathrm{I}} / \mathrm{BINAP}$ is an efficient catalytic system for base-free generation of rhodium carbenes from $N$-tosylhydrazones and their subsequent carbene/alkyne metathesis. ${ }^{1,, 5}$ This reaction provides rhodium vinylcarbenes that can react further in an enantioselective manner. When an alkyne is present in the molecule, a double carbene alkyne metathesis ${ }^{6}$ takes place, providing enantiomerically pure sulfones. ${ }^{5 a}$ On the other hand, when there is an alkene in the molecule, an intramolecular cyclopropanation takes place, efficiently affording chiral vinylcyclopropanes. ${ }^{5 b}$ Continuing with our interest in the cascade cyclization reactions involving rhodium vinylcarbenes, we report that $N$-tosylhydrazone/ alkyne/allene substrates generate a rhodium vinylcarbene that

Institut de Química Computacional i Catàlisi (IQCC) and Departament de Química, Facultat de Ciències, C/Maria Aurèlia Capmany, 69, E-17003-Girona, Catalunya, Spain. E-mail: anna.plaq@udg.edu

$\dagger$ Electronic supplementary information (ESI) available. CCDC 1493175 and 1493176. For ESI and crystallographic data in CIF or other electronic format see DOI: $10.1039 / \mathrm{c} 7 \mathrm{cc} 04803 \mathrm{c}$ reacts with an allene. Unexpectedly the reaction does not follow any of the already reported reaction modes but rather generates a rhodium trimethylenemethane intermediate that formally adds arylsulfinic acid to allow for stereoselective construction of methylenetetrahydropyran scaffolds.

At the outset of this study, linear substrate 1 with NTs tethers (Scheme 1) was synthesized. Under the conditions previously optimized in our earlier studies, ${ }^{5}$ a $28 \%$ yield of an inseparable mixture of two trienic isomers 2 and $2^{\prime}$ in a $2: 1$ ratio was isolated (see Scheme $\mathrm{S} 1$ in the $\mathrm{ESI} \uparrow$ for the mechanistic proposal).

As attempts to improve the reaction conditions, either by decreasing the temperature or by adding a base, were unsuccessful, we decided to place an oxygen tether between the alkyne and the allene. The resulting compound, $3 \mathrm{a}\left(\mathrm{R}=p-\mathrm{C}_{6} \mathrm{H}_{4} \mathrm{CH}_{3}\right)$, was then synthesized and its reactivity was evaluated under the previously described reaction conditions. After one hour of reaction, two products were isolated that, upon complete characterization including X-ray diffraction, ${ }^{7}$ were identified as the 4-methylenetetrahydropyran derivative $(R, R)$-4a and the cyclopentenone derivative 5 (Scheme 2). Although 4a was obtained with excellent enantioselectivity, the reaction showed a low selectivity since the two products were isolated in equal quantities. Due to the relevance of chiral functionalized tetrahydropyran rings in natural products and their use as fragrances and pharmaceuticals, ${ }^{8}$ we sought to develop an efficient synthesis of the methylenetetrahydropyran core taking advantage of the unusual rhodium carbene/ allene reactivity that we had discovered.

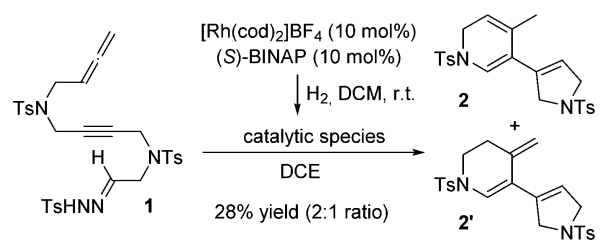

Scheme 1 Cyclization of NTs-tethered substrate 1. 

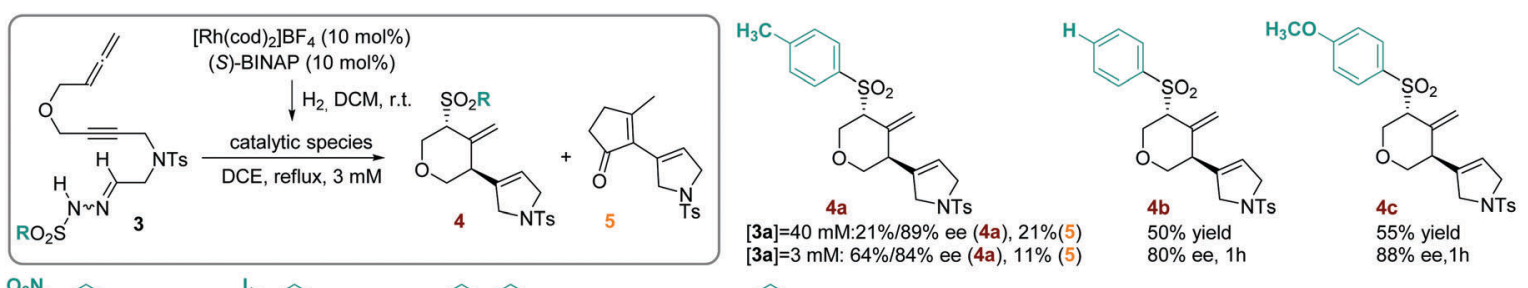

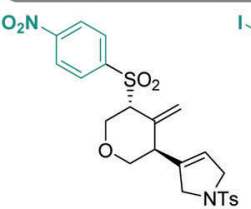

$4 d$ $43 \%$ yield $92 \%$ ee, $24 h$

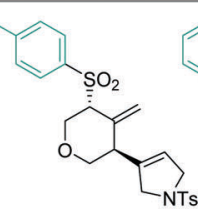

$4 \mathrm{e}$ $41 \%$ yield
$86 \%$ ee, $24 \mathrm{~h}$

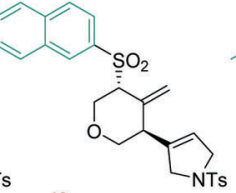

$4 f$ $47 \%$ yield

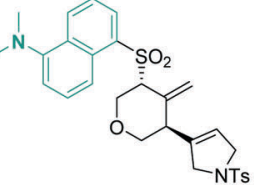

$25 \%$ yield $25 \%$ yield

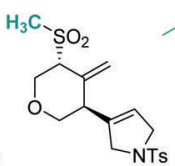

$4 \mathrm{~h}$ $72 \%$ yield $87 \%$ ee, $2.5 \mathrm{~h}$

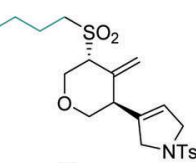

$85 \%$ yield $85 \%$ yield

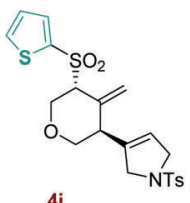

$40 \%$ yield

$90 \%$ yield $24 \mathrm{~h}$

Scheme 2 Rhodium-catalyzed asymmetric cyclization of 3 . Reaction conditions: $0.21 \mathrm{mmol}$ of substrate $\mathbf{3}$ in $70 \mathrm{~mL}$ of dichloroethane (DCE). Cited yields are of isolated products. The stereochemistry of products 4 is assigned with analogy to $\mathbf{4 a}$. Traces of cyclopentenone derivative $\mathbf{5}$ were obtained in the formation of $\mathbf{4} \mathbf{f}$ and $\mathbf{4 g}$.

We therefore proceeded to optimize the reaction conditions, finally finding that the most critical parameter for selectivity was the concentration (see Table S2 in the $\mathrm{ESI} \dagger$ for the optimization). When the reaction was carried out for one hour in lower concentrations ( $3 \mathrm{mM}$ versus $40 \mathrm{mM}$ in our first test), the 4-methylenetetrahydropyran derivative $\mathbf{4 a}$ was obtained in $64 \%$ yield whilst excellent enantioselectivity and a decrease in cyclopentenone derivative $\mathbf{5}$ formation were obtained (Scheme 2). We postulate that the cyclopentenone derivative 5 is formed from a product analogous to 2 (Scheme 1) from which an allyl Claisen rearrangement, followed by a $\mathrm{Rh}^{\mathrm{I}}$-catalyzed alkene hydroacylation, gives the cyclopentenone derivative 5 (see Scheme S1 in the ESI $\dagger$ for the detailed mechanistic proposal).

The scope of the process was then evaluated (Scheme 2). First, a series of substrates with several substituents in the phenyl ring of the sulfonyl hydrazone were reacted to give the corresponding 4-methylenetetrahydropyran derivatives (4b-4e). In all cases the reaction occurred with high enantioselectivity and the sulfonyl group migration was regioselective. ${ }^{9}$ However, when an electronwithdrawing substituent such as nitro (4d) or iodine (4e) was present, the yield dropped and there was a considerable increase in the reaction time. It is noteworthy that a $p-\mathrm{C}_{6} \mathrm{H}_{4} \mathrm{I}$-sulfonyl group is efficiently involved in the reaction (4e), opening the possibility of further transformations of the cyclized compound.

More sterically hindered products, containing either a 2-naphthylsulfonyl (4f) or dansyl (4g) group, were also efficiently obtained although the yields were lower, especially in the case of dansyl. In these two examples, traces of derivative $\mathbf{5}$ were detected, indicating that the less favorable attack of a more sterically hindered sulfinate favors the formation of cyclopentanone derivative 5. Two aliphatic sulfonylhydrazones were also reacted under the optimized conditions. Cyclized products $\mathbf{4 h}$ and $4 \mathbf{i}$ were enantioselectively obtained in high yields. Finally, a 2-thiophenylsulfonylhydrazone-yne-allene substrate $\mathbf{3 j}$ was reacted affording the heteroaromatic derivative $4 \mathbf{j}$ after 24 hours of reaction.

The Ramberg-Bäcklund rearrangement, a base-mediated conversion of $\alpha$-halosulfones, is an excellent option to synthesize regiodefined alkenes. Having synthesized aliphatic sulfones we decided to test their conversion to alkenes. Methylsulfone $\mathbf{4 h}$ was reacted under the Ramberg-Bäcklund rearrangement conditions, by forming in situ the $\alpha$-halosulfones, to generate conjugated triene 6 in $69 \%$ yield (Scheme 3).

To get further insight into the reaction mechanism of the transformation of 3a to 4a, we performed B3LYP/aug-cc-pVDZ$\mathrm{PP} / / \mathrm{B} 3 \mathrm{LYP} / \mathrm{cc}-\mathrm{pVDZ}-\mathrm{PP}$ calculations using reasonable models of the $\mathrm{Rh}^{\mathrm{I}} / \mathrm{BINAP}$ catalyst and reactant $3 \mathrm{a}$ to reduce the computational cost (see Scheme 4 and Computational methods in the ESI $\dagger$ for more detailed information). The reported energies are Gibbs energies that incorporate the effect of dichloroethane solution.

Scheme 4 shows the Gibbs energy profile for the transformation of the reactant 3a into the final product $(R, R)-\mathbf{4 a}$. In the first step, the $\mathrm{Rh}^{\mathrm{I}} / \mathrm{BINAP}$ catalyst coordinates to $3 \mathrm{a}$ through the $\mathrm{N}$ electron pair and $\eta^{2}$ with the $\pi$-system of the alkyne group to form intermediate $\mathbf{B}$ in an endergonic process $\left(5.1 \mathrm{kcal} \mathrm{mol}^{-1}\right)$. B evolves to $\mathbf{C}$ by means of a $\mathbf{H}$ transfer combined with the breaking of the Rh-N initial coordination and the formation of a $\mathrm{N}=\mathrm{N}$ double bond and a $\mathrm{Rh}-\mathrm{C}$ bond. The Gibbs energy barrier for the conversion of $3 \mathbf{a}$ to $\mathbf{C}$ is $27.2 \mathrm{kcal} \mathrm{mol}^{-1}$ (see Fig. S70 in the ESI $\dagger$ for the molecular structure of TS_BC). C yields D through TS_CD with a barrier of $8.3 \mathrm{kcal} \mathrm{mol}^{-1}$ in a complex process that involves the release of $\mathrm{N}_{2}$, the generation of the $\mathrm{Ts}^{-}$group, and the formation of a $\mathrm{Rh}=\mathrm{C}$ bond. Then, an almost barrierless carbene/alkyne metathesis of $\mathbf{D}$ leads to intermediate $\mathbf{E}$.

The relative Gibbs energy of $\mathbf{E}$ with respect to our model of $3 \mathbf{a}$ and $\mathrm{Rh}^{\mathrm{I}} / \mathrm{BINAP}$ is $-68.1 \mathrm{kcal} \mathrm{mol}^{-1}$ in dichloroethane. $\mathbf{E}$ is a rhodium(I) species in a square pyramidal coordination geometry

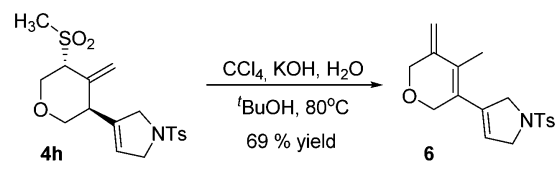

Scheme 3 Ramberg-Bäcklund rearrangement of $\mathbf{4 h}$. 


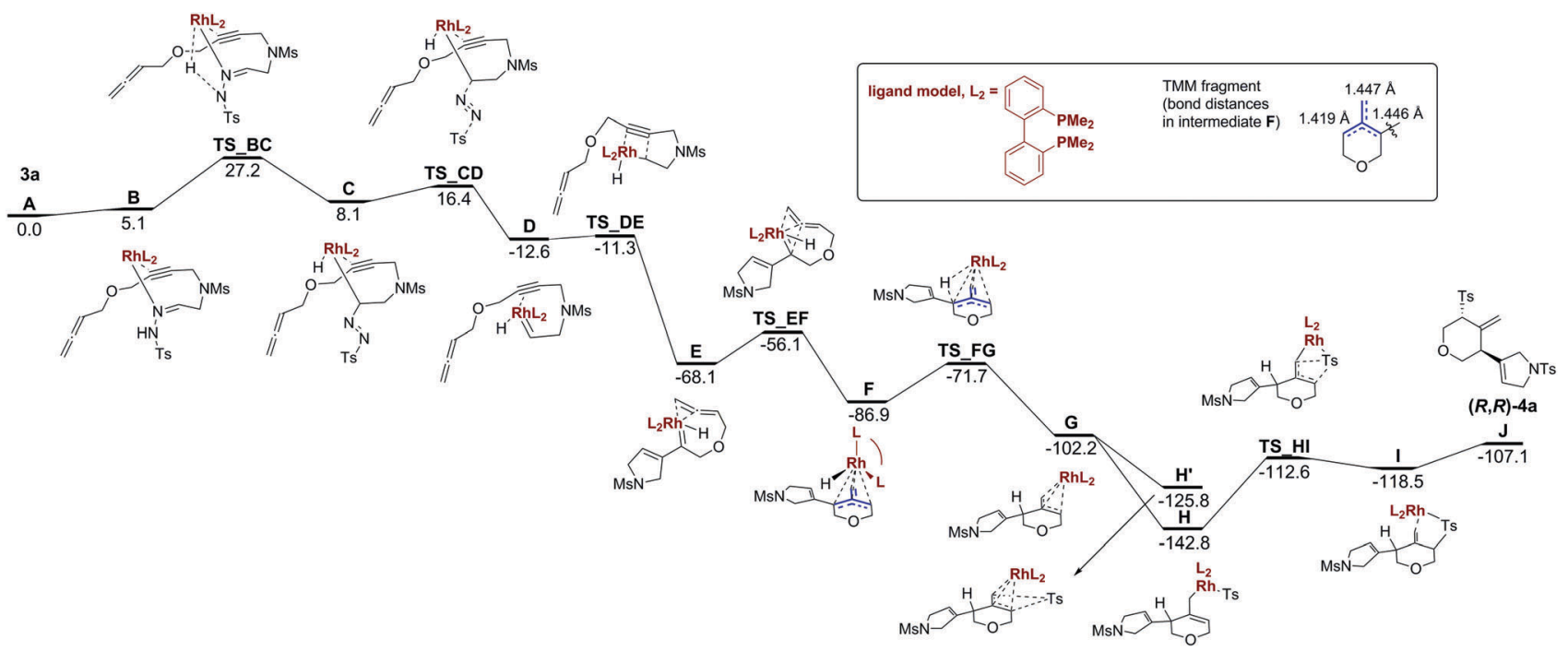

Scheme 4 Gibbs energy profile ( $\mathrm{kcal} \mathrm{mol}^{-1}$ ) for the $\mathrm{Rh}^{1}$ catalyzed transformation of $\mathbf{3 a}$ into $(R, R)-\mathbf{4 a}$. Intermediates and TS from $\mathbf{B}$ to TS_CD and from $\mathbf{H}$ and $\mathbf{H}^{\prime}$ to $\mathbf{I}$ have +1 charge. Intermediates and TS from $\mathbf{D}$ to $\mathbf{G}$ have +2 charge.

in which the $\pi$-system of the external double bond of the allene group interacts with the $\mathrm{d}$ orbitals of the metal in a basal position and the hydride occupies the apical position. Ring closure through a [2+2] cycloaddition of the double bond of the external allene and the rhodium-carbene double bond develops a strained rhodacyclobutane that is not stable and rearranges to form intermediate $\mathbf{F}$ in an exergonic process $\left(18.8 \mathrm{kcal} \mathrm{mol}^{-1}\right)$ that takes place through a barrier of $8.0 \mathrm{kcal} \mathrm{mol}^{-1}$ (see Fig. S73 in the ESI $\dagger$ for the molecular structure of TS_EF). Intermediate $\mathbf{F}$ had an electronic structure resembling that of trimethylenemethane (fragment in blue in Scheme 4). The biradical $\pi$-system of the 4-methylenetrihydropyran ring is stabilized by a facial $\eta^{3}$-coordination to the metal so that the intermediate $\mathbf{F}$ formed has a closed-shell electronic ground state. The binding is essentially symmetric with respect to the three $\mathrm{C}-\mathrm{C}$ bonds (see the $\mathrm{C}-\mathrm{C}$ bond distances in the inset of Scheme 4) with the rhodium located in a central position. ${ }^{10}$ Moreover, the similar Rh-C bond distances of $2.17,2.21$, and $2.29 \AA$ confirm this almost symmetric arrangement.

Trimethylenemethane (TMM) diyl intermediates have been invoked in the tandem cycloaddition reaction of allenyl diazo compounds forming triquinane structures. ${ }^{11}$ In this metal-free process, the TMM diyl, constrained as a part of a ring, intramolecularly reacts with a tethered alkene in a formal [3+2] cycloaddition. The TMM reactivity can also be exploited in synthetic applications when complexed to a metal centre. ${ }^{12}$ Rhodium-bound TMM has also been invoked by Sarpong et al. in the synthesis of 3,4-fused pyrroles by the reaction of an imino rhodium carbene - generated by the decomposition of $N$-sulfonyl-1,2,3-triazoles - and a tethered allene. ${ }^{4 a}$ The rhodiumbound TMM again reacts in a formal [3+2] cycloaddition. An intermolecular variation has also been reported by Murakami et al. using nickel as the catalyst. ${ }^{4 b}$ In the reaction under study, the rhodium-bound trimethylenemethane $\mathbf{F}$ evolves through a reverse $\beta$-H-elimination via TS_FG that transfers the $\mathrm{H}$ atom from
$\mathrm{Rh}$ to the $\mathrm{C}$ atom attached to the 2,5-dihydropyrrole substituent to yield G. This process is exergonic by $15.3 \mathrm{kcal} \mathrm{mol}^{-1}$ and has to surpass a barrier of $15.2 \mathrm{kcal} \mathrm{mol}^{-1}$. In the next step, the $\mathrm{Ts}^{-}$group coordinates to $\mathrm{Rh}$ to yield intermediate $\mathbf{H}$, which has a square pyramidal geometry with the diphosphine ligand and the $\mathrm{Ts}^{-}$group, coordinating in a bidentate fashion, occupying the basal positions. This process is exergonic by $40.6 \mathrm{kcal} \mathrm{mol}^{-1}$. An alternative pathway through $\mathbf{H}^{\prime}$ (Scheme 4) in which the $\mathrm{Ts}^{-}$ group directly attacks the other side of the 4-methylenetrihydropyran ring of intermediate $\mathbf{G}$ without prior coordination to $\mathrm{Rh}$ is also possible, although this alternative is energetically less favourable. From $\mathbf{H}$, an intramolecular nucleophilic attack of the $\mathrm{Ts}^{-}$group to $\mathbf{C} 5$ of the dihydropyran ring takes place to yield $\mathbf{I}$, in which the final trans-disubstituted product $(R, R)$-4a coordinated to the metal has already been formed. This attack is endergonic by $24.3 \mathrm{kcal} \mathrm{mol}^{-1}$ and has to surmount a barrier of $30.2 \mathrm{kcal} \mathrm{mol}^{-1}$ (see Fig. S79 in the ESI $\dagger$ for the molecular structure of TS_HI). This, therefore, is the rate-determining step (rds) of the reaction mechanism. It would be expected that this step would have higher barriers for systems with electron-withdrawing substituents such as $\mathbf{4 d}$ or $\mathbf{4 e}$ or sterically hindered sulfinates such as $\mathbf{4 f}$ or $\mathbf{4 g}$. The final release of 4a costs an additional energy of $11.4 \mathrm{kcal} \mathrm{mol}^{-1}$. However, it is likely that the release of $\mathbf{4 a}$ would be assisted by the addition of 3a to reduce or even remove this energetic cost. The transformation of reactants $\mathbf{3 a}$ to the product $(S, S)$-4a (the enantiomer of the experimentally obtained product $(R, R)$-4a) via an alternative diastereomeric route is also possible (see Section S.14 and Scheme S2 in the ESI $\dagger)$. However, the route that leads to $(S, S)$-4a has an rds with a barrier that is $2.7 \mathrm{kcal} \mathrm{mol}^{-1}$ higher in energy than that of the pathway shown in Scheme 4 . This energy difference in the barrier of the rds justifies the experimental formation of only $(R, R)-4 \mathbf{a}^{13}$

Further evidence supporting the postulated mechanism was gained by carrying out a deuterium-labelling experiment. The treatment of substrate $3 \mathbf{e}$ with deuterated water afforded the 
deuterium-labelled compound 3e-D. Upon cyclization, NMR characterization confirmed that the deuterium was selectively incorporated into the 5-position of the tetrahydropyran ring (see ESI $\dagger$ ).

In conclusion, we have developed an enantioselective synthesis of 4-methylenetetrahydropyran derivatives that rely on the reaction of rhodium vinyl carbenes and allenes as a key step. This cyclization reaction represents an efficient synthesis of transdisubstituted methylenetetrahydropyrans that has revealed a highly unusual reactivity pattern in carbene/allene chemistry. DFT calculations show that a rhodium-bound trimethylenemethane intermediate is involved which has formally added arylsulfinic acid in an enantioselective manner. It is important to highlight that asymmetric variants of the transition-metal catalyzed [3+2] cycloaddition involving TMM remained elusive for a long period of time ${ }^{14}$ and that enantioselective additions of pronucleophiles are even rarer. The rate-determining step is the nucleophilic intramolecular attack of the $\mathrm{Ts}^{-}$group to the tetrahydropyran ring.

We are grateful for the financial support by the Spanish Ministry of Economy and Competitiveness (MINECO) (Project CTQ2014-54306-P) and the Generalitat de Catalunya (Project 2014-SGR-931, Xarxa de Referència en Química Teòrica i Computacional, ICREA Academia 2014 prize for M. S., and FI predoctoral grant to Oे. T.). The EU under the FEDER grant UNGI10-4E-801 has also funded this research. We thank one of the anonymous reviewers for his/her constructive and helpful suggestion on the two diastereomeric pathways.

\section{Conflicts of interest}

There are no conflicts to declare.

\section{Notes and references}

1 For selected reviews, see: $(a)$ H. M. L. Davies and J. R. Manning, Nature, 2008, 451, 417; (b) A. Padwa, Chem. Soc. Rev., 2009, 38, 3072; (c) M. P. Doyle, R. Duffy, M. Ratnikov and L. Zhou, Chem. Rev., 2010, 110, 704; (d) X. Zhao, Y. Zhang and J. Wang, Chem. Commun., 2012, 48, 10162; (e) Q. Xiao, Y. Zhang and J. Wang, Acc. Chem. Res., 2013, 46, 236; $(f)$ D. Gillingham and N. Fei, Chem. Soc. Rev., 2013, 42, 4918; $(g)$ A. Ford, H. Miel, A. Ring, C. N. Slattery, A. R. Maguire and M. A. McKervey, Chem. Rev., 2015, 115, 9981; (h) Oे. Torres and A. Pla-Quintana, Tetrahedron Lett., 2016, 57, 3881.

2 A. B. Charette, M.-N. Roy and V. N. G. Lindsay, in Cyclopropanation Reactions in Stereoselective Reactions of Carbon-Carbon Double Bonds, ed. J. G. de Vries, Science of Synthesis Series, Thieme, Stuttgart, 2011, vol. 1, ch. 1.14, pp. 731-817.

3 (a) G. Audran and H. Pellissier, Adv. Synth. Catal., 2010, 352, 575; (b) C. S. Adams, C. D. Weatherly, E. G. Burke and J. M. Schomaker, Chem. Soc. Rev., 2014, 43, 3136; (c) A. Brandi, S. Cicchi, F. M. Cordero and A. Goti, Chem. Rev., 2014, 114, 7317.

4 (a) E. E. Schultz and R. Sarpong, J. Am. Chem. Soc., 2013, 135, 4696; (b) T. Miura, K. Hiraga, T. Biyajima, Y. Nakamuro and M. Murakami, Org. Lett., 2013, 15, 3298; (c) E. López, G. Lonzi, J. González and L. A. López, Chem. Commun., 2016, 52, 9398; (d) R. R. Singh, S. K. Pawar, M.-J. Huang and R.-S. Liu, Chem. Commun., 2016, 52, 11434. 5 (a) Ò. Torres, T. Parella, M. Solà, A. Roglans and A. Pla-Quintana, Chem. - Eur. J., 2015, 21, 16240; (b) O. Torres, A. Roglans and A. Pla-Quintana, Adv. Synth. Catal., 2016, 358, 3512.

6 (a) A. Padwa and M. D. Weingarten, Chem. Rev., 1996, 96, 223; (b) A. Padwa, J. Organomet. Chem., 2000, 610, 88.

7 CCDC 1493176 (compound $(R, R)-4 a$ ) and 1493175 (compound 5) contains the supplementary crystallographic data for this paper. The thermal ellipsoids in the ORTEP plot of the X-ray structure of compound $(R, R)-\mathbf{4 a}$ and $\mathbf{5}$ are drawn at $\mathbf{5 0 \%}$ probability.

8 P. A. Clarke and S. Santos, Eur. J. Org. Chem., 2006, 2045.

9 The sulfonyl group is stereo- and regioselectively incorporated in the cyclized product independently of the electronics of the substituent. This contrasts with the decreased regioselectivity observed in our previous study (see ref. $5 a$ ) when electron-withdrawing substituents were present on the sulfonylhydrazone moiety.

10 S. Mazumder, D. Shang, D. E. Negru, M.-H. Baik and P. A. Evans, J. Am. Chem. Soc., 2012, 134, 20569.

11 H.-Y. Lee, Acc. Chem. Res., 2015, 48, 2308.

12 (a) B. M. Trost, Angew. Chem., Int. Ed. Engl., 1986, 25, 1; (b) I. Nakamura and Y. Yamamoto, Adv. Synth. Catal., 2002, 344, 111.

13 An alternative mechanism involving similar steps to those found in the $[2+2+2]$ cycloadditions was also studied (see Scheme S3 in the $\mathrm{ESI} \dagger$ ) but was ruled out since the Gibbs energy barrier for one of the steps was higher than $40 \mathrm{kcal} \mathrm{mol}^{-1}$.

14 B. M. Trost, S. M. Silverman and J. P. Stambuli, J. Am. Chem. Soc., 2011, 133, 19483. 